\title{
PENINGKATAN KESEHATAN MASYARAKAT MELALUI PEMBERDAYAAN WANITA DALAM PEMANFAATAN LAHAN PEKARANGAN DENGAN TANAMAN OBAT KELUARGA (TOGA)
}

\section{(The Increasing Of Community Health Through Empowerment Thewomen In The Utilization Of The Yard With Family Medicine Plants)}

\author{
Suaibatul Aslamiah, Ise Afitah dan Mariaty \\ Program Studi Kehutanan Fakultas Kehutanan dan Pertanian \\ Universitas Muhammadiyah Palangkaraya \\ JI. RTA Milono Km.1,5 Palangka Raya, Kalimantan Tengah 73111 \\ e-mail : suaibatul99@yahoo.co.id ${ }^{1}$, afitah78@yahoo.com² ${ }^{2}$ iyoet kapuas@yahoo.com
}

\begin{abstract}
This service activities carried out in the village Langkai slender Pahandut districts in community groups Perumahaan Borneo. The selection of this location because in general, the women in the village built is not working, so had plenty of time to become empowered and more rapidly in accepting teknologi. This activity aims to help mothers and young women to improve family health by reducing expenses in medicine and improve the utilization of the yard with plant that function as medicinal plants. Application activity is the introduction of several types of plants that serve as a remedy. In some women there who are already active in exploiting the yard, then the implementation of the activities is the enrichment kind of TOGA and fuction.

The method used is planting demonstration counseling and mentoring. Activity results showed that women in the target group in two groups RT Borneo and Candra Buana group has formed a TOGA garden in her yard. Evaluation of this activity is a very good response, each group in two households has a garden TOGA, so the evaluation is the increased utilization of the yard seventy-five percent.
\end{abstract}

Keywords: medicinal; plants

\section{Abstrak}

Kegiatan pengabdian ini dilaksanakan di Desa Langkai, Kecamatan Pahandut, pada Kelompok masyarakat binaan Perumahan Borneo. Pemilihan lokasi ini karena pada umumnya ibu-ibu di desa binaan tersebut tidak bekerja, sehingga mempunyai banyak waktu untuk diberdayakan dan lebih cepat dalam menerima Teknologi. Kegiatan ini bertujuan membantu para ibu dan remaja putri untuk meningkatkan kesehatan keluarga dengan mengurangi pengeluaran dalam membeli obat dan meningkatkan pemanfaatan pekarangan dengan tanaman yang berfungsi sebagai obat. Penerapan kegiatan adalah dengan introduksi beberapa jenis tanaman yang berfungsi sebagai obat. Pada beberapa ibu ada yang sudah aktif dalam memanfaatkan pekarangan, maka penerapan kegiatan adalah pengkayaan jenis TOGA dan fungsinya. Metode yang digunakan adalah penyuluhan, demonstrasi penanaman dan pendampingan. Hasil kegiatan menunjukkan bahwa kaum wanita di kelompok binaan di dua RT Kelompok Borneo dan Kelompok Candra Buana telah membentuk taman Toga di pekarangannya. Evaluasi kegiatan ini adalah, respon sangat baik, setiap kelompok di dua RT mempunyai taman TOGA, jadi evaluasinya adalah terjadi peningkatan pemanfaatan pekarangan tujuh puluh lima persen.

Kata kunci: Tanaman, Obat 


\section{PENDAHULUAN}

\section{Analisis Situasi}

Sistem Kesehatan Nasional adalah suatu tatanan yang mencerminkan upaya bangsa Indonesia untuk meningkatkan kemampuan mencapai derajat kesehatan yang optimal sebagai perwujudan kesejahteraan umum. Flora dan fauna serta mineral yang berkhasiat sebagai chat harus dikembangkan dan disebar luaskan agar semaksimal mungkin dapat dimanfaatkan dalam upaya-upaya kesehatan masyarakat. Khususnya untuk tanaman obat penyebar luasannya dapat dilakukan melalui TOGA (tanaman obat keluarga).

Toga adalah singkatan dari tanaman obat keluarga. Taman obat keluarga pada hakekatnya sebidang tanah baik di halaman rumah, kebun ataupun ladang yang digunakan untuk membudidayakan tanaman yang berkhasiat sebagai obat dalam rangka memenuhi keperluan keluarga akan obat-obatan. Kebun tanaman obat atau bahan obat dan selanjutnya dapat disalurkan kepada masyarakat, khususnya obat yang berasal dari tumbuh-tumbuhan.

Tanaman obat keluarga akhir-akhir ini lebih ngetrend di mata masyarakat. Obat-obatan tradisional juga lebih tepat untuk digunakan sebagai pencegah penyakit atau untuk menjaga kesehatan. Dewasa ini obat-obatan modern dari berbagai macam bentuk sudah dijual bebas, mudah sekali didapatkan dengan harga yang dapat terjangkau dan sudah menjadi bagian dari kehidupan seluruh lapisan masyarakat. TOGA (Taman Obat Keluarga) sudah dikenal masyarakat yang memuat beberapa manfaat tanaman obat yang sebagai salah satu usaha pendukung untuk meningkatkan fungsi dan manfaat lahan pekarangan baik di rumah, sekolah, maupun perkantoran. Lahan pekarangan biasanya memiliki luas lahan terbatas dan mempunyai sifat berbeda dengan kebun atau ladang, maka jenis tanaman obat sebaiknya dipilih yang penting dan bermanfaat, juga harus memperhatikan faktor keindahan serta memperhatikan kondisi halaman, kontur tanah, mudah dibudidayakan, tidak menyita tempat, dan bentuk serta adanya pohon atau bangunan lain. Faktor paling penting dalam mengatur lahan untuk tanaman obat adalah memperhatikan keindahan, tidak merusak/ mengganggu pemandangan juga harus diperhatikan keberadaan elemen taman lain (pohon peneduh atau tanaman hias lain, kandang ternak, tiang bendera, lampu penerang jalan, jalan setapak, kolam ikan dan lain-lain).

Berbicara tentang pemanfaatan tanaman obat atau bahan obat alam pada umumnya sebenarnya bukanlah merupakan hal yang baru. Sejak terciptanya manusia di permukaan bumi, telah diciptakan pula alam sekitarnya mulai dari itu pula manusia mulai mencoba memanfaatkan alam sekitarnya untuk memenuhi keperluan alam kehidupannya, termasuk keperluan akan obatobatan dalam rangka mengatasi masalahmasalah kesehatan yang dihadapinya. Kenyataan menunjukkan bahwa dengan bantuan obatobatan asal bahan alam tersebut, masyarakat dapat mengatasi masalah-masalah kesehatan yang dihadapinya. Hal ini menunjukkan bahwaobatt yang berasal dari sumber bahan alam khususnya tanaman telah memperlihatkan peranannya dalam penyelenggaraan upayaupaya kesehatan masyarakat. Adapun pemanfaatan TOGA yang digunakan untuk pengobatan gangguan kesehatan keluarga 
menurut gejala umum adalah: demam panas, batuk, sakit perut dan gatal-gatal.

\section{Permasalahan}

Pemanfaatan pekarangan di perkotaan mempunyai banyak keuntungan terutama dalam meningkatan pendapatan keluarga misalnya sebagai warung hidup, lumbung hidup, apotek hidup, sehingga perlu dikembangkan secara intensif. Kenyataan saat ini, harga obat saat ini sangat tinggi dan lebih sering lagi dokter tidak ada. Oleh karena itu penyediaan tanaman yang berfungsi sebagai obat herbal di pekarangan sangat membantu keluarga mengatasi masalah kesehatan.

Tanaman obat sebenarnya memiliki fungsi ganda selain sebagai dekorasi halaman, tanaman obat berfungsi sebagai ramuan alami untuk mengobati berbagai penyakit yang seringkali timbul. Masyarakat dewasa ini belum memahami bahwa tanaman obat selain sangat berguna buat menyembuhkan berbagai penyakit, tanaman ini juga banyak dibutuhkan oleh industri obat-obatan, rumah sakit, dan perusahaan-perusahaan yang bergerak dibidang penjualan produk kesehatan.

Beberapa ahli herbalis yakin bahwa pemanfaatan bahan-bahan yang bersifat alamiah lebih diterima (acceptable) oleh tubuh manusia dibandingkan dengan penggunaan bahan-bahan yang bersifat sintetik, walaupun mereka tahu betul bahwa khasiat pemanfaatan bahan-bahan yang alami cenderung relatif lambat. Kini, kecendrungan untuk kembali ke alam sudah bersifat global, ditandai dengan maraknya produk bahan alam baik dari dalam maupun dari luar negeri dengan berbagai macam label dan merk.
Penyampaian program kepada masyarakat perlu dilaksanakan dan selalu dievaluasi hasilnya agar benar-benar berhasil. Penyuluhan harus juga disertai dengan demonstrasi program, karena dengan melihat hasil demonstrasi, masyarakat akan lebih mudah memahami dan dengan senang hati meniru program yang dicontohkan. Tentunya hal ini tidak serta merta berhasil, perlu langkah-langkah dalam setiap seksi kegiatan.

\section{Tujuan}

Kegiatan pengabdian kepada masyarakat ini dilakukan untuk membantu para ibu dan remaja putri untuk meningkatkan kesehatan keluarga dengan mengurangi pengeluaran dalam membeli obat, dan meningkatkan pemanfaatan pekarangan dengan tanaman yang berfungsi sebagai obat.

\section{METODE PELAKSANAAN}

\section{Waktu dan Tempat}

Kegiatan pengabdian masyarakat ini dilaksanakan pada Kelompok Masyarakat Binaan Perumahan Borneo yang terletak di Jalan RTA. Milono Km 6,5 Desa Langkai Kecamatan Pahandut Provinsi Kalimantan Tengah. Jarak kampus dari lokasi kegiatan kurang lebih berjarak $5 \mathrm{~km}$ dan dapat ditempuh dengan menggunakan alat transportasi kendaraan roda dua ataupun roda empat. Demi kelancaran kegiatan ini sebelumnya kami telah berkomunikasi dengan ketua PKK setempat untuk mengatur jadwal kegiatan hingga hari pelaksanaan dan berakhirnya kegiatan. 


\section{Sasaran Kegiatan}

Masyarakat sasaran dalam pengabdian ini adalah para ibu-ibu dan remaja putri di lingkungan komplek perumahan Borneo. Kaum wanita di lingkungan ini memiliki kemampuan dan daya kreativitas yang tinggi dalam menunjang perekonomian keluarga.

\section{Metode Kegiatan}

1. Memberikan pembelajaran kepada masyarakat sekitar sebagai wujud pengabdian kepada masyarakat.

2. Penyuluhan disertai dengan simulasi peragaan penanaman tanaman obat keluarga (TOGA) sesuai ilmu Pertanian dan Kehutanan dalam arti luas.

3. Memberi keterampilan kepada masyarakat di dalam efisiensi pemanfaatan lahan dan memberikan nilai ekonomis.

4. Membuka wacana dan kreativitas kelompok masyarakat khususnya kelompok wanita untuk lebih maju.

5. Memantau perkembangan dan mencatat semua hasil penyuluhan terhadap hasil kegiatan yang dilakukan oleh masyarakat setelah diadakan penyuluhan.

\section{Solusi yang Ditawarkan}

Pola pendekatan kepada warga sekitar melalui sosialisasi tentang partisipasi sivitas akademika universitas muhammadiyah palangkaraya dalam bentuk penyuluhan serta memberikan pemahaman kepada warga tentang pentingnya menjaga kesehatan dan mau menanam tanaman-tanaman yang berguna bagi kesehatan keluarga. Memberikan contoh kegiatan pola-pola penanaman sesuai dengan kaidah ilmu silvikultur dan budidaya tanaman pertanian yang tepat dan sesuai. Kesesuaian ini berdasarkan sistem perakaran, sifat tanah, dan sifat tanaman sehingga polanya sesuai dengan kaidah ilmu tumbuhan, maka lahan tersebut akan mempunyai produktivitas yang maksimal.

Salah satu fungsi Toga adalah sebagai sarana untuk mendekatkan tanaman obat kepada upaya-upaya kesehatan masyarakat yang antara lain meliputi:

1. Upaya preventif (pencegahan)

2. Upaya promotif (meningkatkan derajat kesehatan)

3. Upaya kuratif (penyembuhan penyakit) Selain fungsi diatas ada juga fungsi lainnya yaitu:

1. Sarana untuk memperbaiki status gizi masyarakat, sebab banyak tanaman obat yang dikenal sebagai tanaman penghasil buah-buahan atau sayur-sayuran misalnya lobak, saledri, pepaya dan lain-lain.

2. Sarana untuk pelestarian alam Apabila pembuatan tanaman obat alam tidak diikuti dengan upaya-upaya pembudidayaannya kembali, maka sumber bahan obat alam itu terutama tumbuh tumbuhan akan mengalami kepunahan.

3. Sarana penyebaran gerakan penghijauan. Untuk menghijaukan bukit-bukit yang saat ini mengalami penggundulan, dapat dianjurkan penyebarluasan penanaman tanaman obat yang berbentuk pohon-pahon misalnya pohon asam, pohon kedaung, pohon trengguli dan lain-lain.

4. Sarana untuk pemerataan pendapatan Toga disamping berfungsi sebagai sarana untuk menyediakan bahan obat bagi 
keluarga dapat pula berfungsi sebagai sumber penghasilan bagi keluarga tersebut.

5. Sarana keindahan

Dengan adanya Toga dan bila di tata dengan baik maka hal ini akan menghasilkan keindahan bagi orang/masyarakat yang ada di sekitarnya. Untuk menghasilkan keindahan diperlukan perawatan terhadap tanaman yang di tanam terutama yang ditanam di pekarangan rumah.

\section{HASIL DAN PEMBAHASAN}

Kelompok Binaan Perumahan Borneo terbagi kedalam 2 kelompok, yaitu kelompok Borneo dan kelompok Candra Buana. Masing-masing kelompok terdiri dari $5 \mathrm{KK}$. Jumlah tanaman obat di pekarangan dapat dilihat pada tabel jenis tanaman obat
Dari Tabel Jenis Tanaman Obat , tampak jenis tanaman obat sudah sangat bervariasi, dominan adalah dari kelompok jahe-jahean misalnya jahe merah (Zingiber officinale Linn.), sambiloto (Androgaphis paniculata), rumput mutiara (Hedyotis corymbosa), soka (Ixora sricta), alang-alang (Imperata cylindrica) dan sirih (Piper betle).

Evaluasi dari jumlah kehadiran setiap pertemuan hampir (75\%) datang dan aktif, karena para ibu sadar akan manfaatnya. Hal ini tampak dari partisipasi mereka menanam tanaman TOGA, dan aktifnya bertanya tentang pemanfaatan tanaman obat dan memelihara tanaman TOGA per kelompok.

Tabel . Jenis tanaman obat di 2 kelompok binaan di desa Langkai Kecamatan Pahandut.

\begin{tabular}{|c|c|c|}
\hline No & Nama Kelompok & Jenis TOGA \\
\hline & I. Kelompok Borneo & \\
\hline 1 & Melati & $\begin{array}{l}\text { 1. Jahe merah (Zingiber officinale Linn.var.rubrum) } \\
\text { 2. Temulawak ( Cucurma xanthorrhiza) } \\
\text { 3. Lidah buaya ( Aloe vera) } \\
\text { 4. Sambiloto (Androgaphis paniculata (Burm.f.) Nees.) } \\
\text { 5. Jambu biji merah } \\
\text { 6. Bunga Mawar (Rosa chinensis Jacq.) } \\
\text { 7. Sirih hijau (Piper ningrum) } \\
\text { 8. } \quad \text { Belimbing buah } \\
\text { 9. Sirsak }\end{array}$ \\
\hline 2 & Anggrek & $\begin{array}{l}\text { 1. } \text { Daun sendok (Plantago mayor.L) } \\
\text { 2. Kumis kucing (Orthosiphon spicatus B.B.S) } \\
\text { 3. Temu-temuan (Curcuma) } \\
\text { 4. } \text { Mangga } \\
\text { 5. Soka ( Ixora sricta) } \\
\text { 6. Pepaya } \\
\text { 7. } \text { Bandotan (Ageratum conyzoides L.) } \\
\text { 8. Seledri (Apium gravieoles) } \\
\text { 9. Sawo }\end{array}$ \\
\hline
\end{tabular}




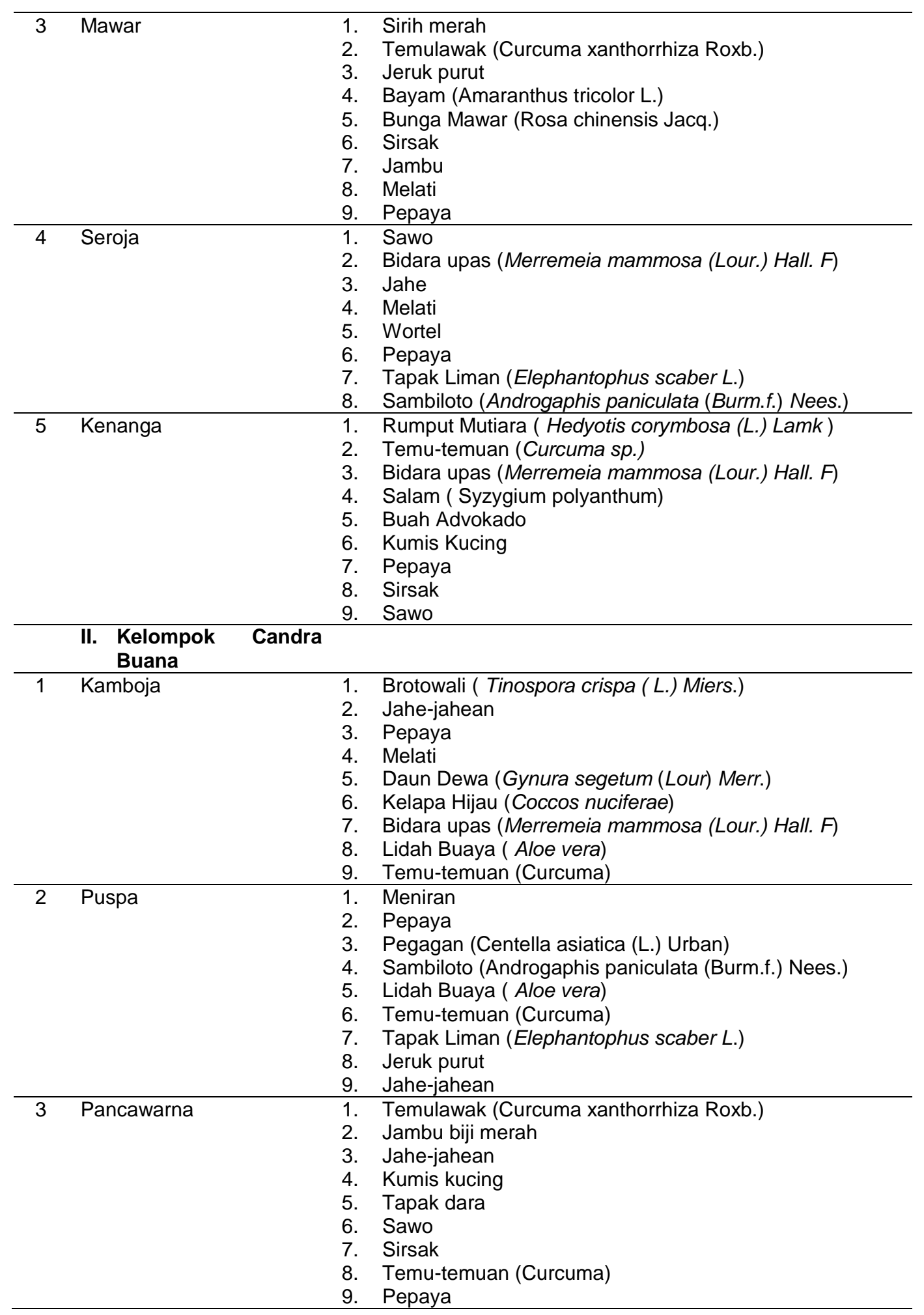




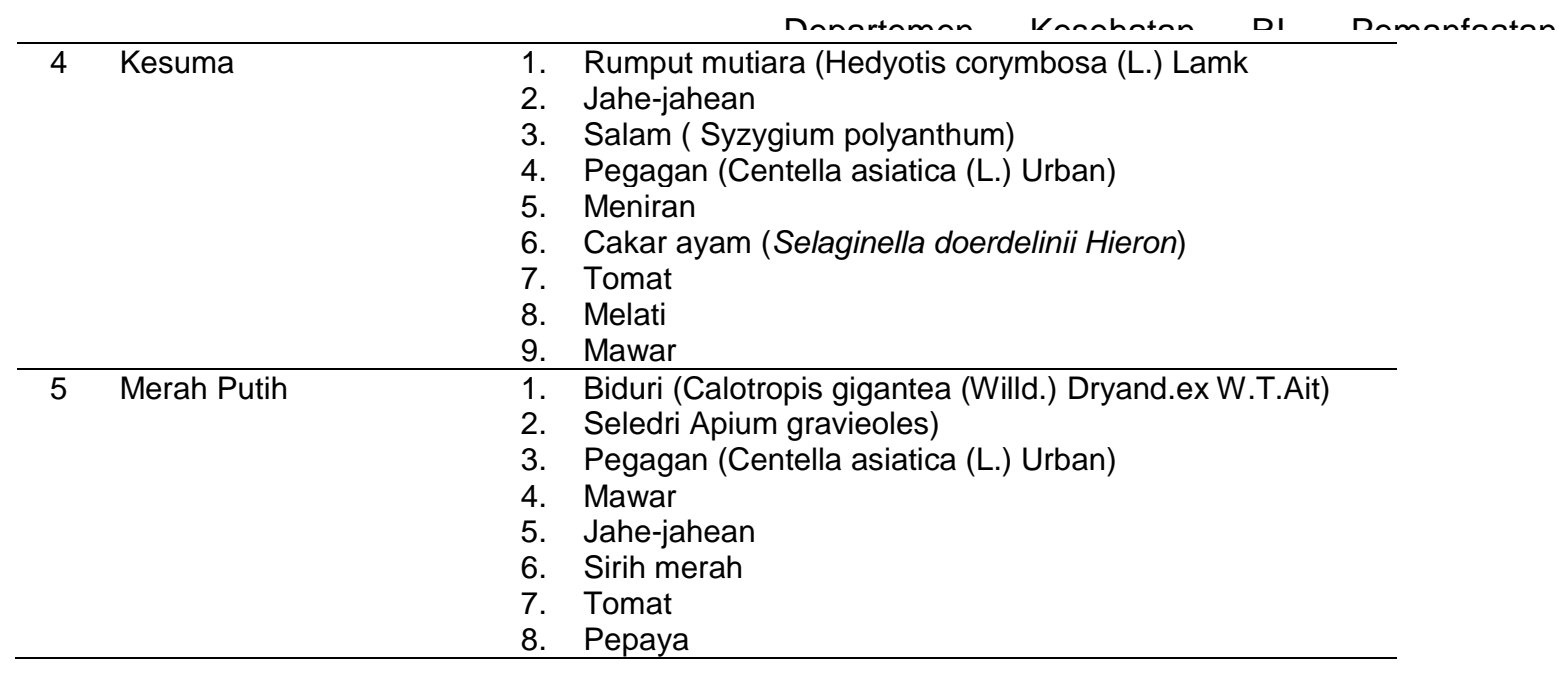

\section{SIMPULAN DAN SARAN}

\section{Simpulan}

Pemanfaatan pekarangan dengan TOGA sangat dirasakan manfaat dan kegunaannya, hal ini tampak dari partisipasi dan keterlibatan seluruh anggota kelompok ibu-ibu dan remaja putri di lingkungan perumahan Borneo ketika penyuluhan dan demonstrasi penanaman tanaman TOGA, dan kelanjutan perawatannya.

\section{Saran}

Kami berharap program pengabdian yang telah dilaksanakan dapat memberikan nilai tambah bagi masyarakat sekitar dan dapat diaplikasikan dalam kehidupan sehari-hari tidak hanya pada saat program pengabdian berlangsung akan tetapi dapat tumbuh berakar disetiap sendi kehidupan masyarakatnya.

\section{DAFTAR PUSTAKA}

Departemen Kesehatan RI. Tanaman Chat Keluarga Edisi III. Jakarta 1983.
Departemen Kesehatan RI. Misteri Modika Indonesia Jilid I dan II. Jakarta 1983.

Departemen Kesehatan RI. Pemanfaatan Tanaman Obat. Jakarta 1992.

Dalimartha, S. 2000. Atlas Tumbuhan Obat Indonesia jilid 2. Penerbit Trubus Agriwidya, Jakarta.

Mahendra, B. 2006. Panduan Meracik Herbal. Penerbit Penebar Swadaya, Jakarta 